\title{
Effect of Light on Growth and Sporulation of Aspergillus ornatus
}

\author{
By E. P. HILL \\ Department of Biology, Macalester College, St Paul, Minnesota 55I05, U.S.A.
}

(Received 15 September 1975; revised 5 January 1976)

\begin{abstract}
SUMMARY
Aspergillus ornatus produces conidia when grown in continuous light but few, if any, when grown in continuous darkness. A minimum of $3 \mathrm{~h}$ of exposure to light is needed for induction. Light inhibits growth, glucose uptake and phosphorylation but does not inhibit the uptake of lysine. A low molecular weight substance produced or accumulating in the light inhibits the phosphorylation of glucose. It is suggested that the inhibition of glucose uptake and phosphorylation precedes conidiation and that conidiation may be the result of starvation caused by this light-induced inhibition.
\end{abstract}

\section{INTRODUCTION}

Changed growth rate or yield, spore production and pigment formation are among the responses of many fungi to light (Carlile, I 965, I970). The Ascomycetes and Fungi Imperfecti have received considerable attention, since exposure to light markedly affects asexual sporulation. Aspergillus flavus (Muntanjola-Cvetkovic \& Neskovic, I968) and Trichoderma viride (Gressel \& Galun, 1967) produce conidia after exposure to light, but few, if any, when incubated in constant darkness.

Aspergillus ornatus, reported as a new species by Raper, Fennell \& Treasner (I953), produces abundant conidia when grown in continuous light and virtually none when grown in the dark. Furthermore, cleistothecia and ascospores are produced in the dark whereas neither are produced in continuous light. Schwemmin (I960) has shown that the fungus has the capacity to switch between these sporulation mechanisms as a result of illumination. This fungus appears to provide a good system for studying the mechanism of light-mediated morphogenesis.

\section{METHODS}

Growth of the organism. Aspergillus ornatus ATCCI692 I was obtained from Professor A. S. Sussman. It was grown static, unless otherwise indicated, in $25 \mathrm{ml}$ Erlenmeyer flasks containing $4 \mathrm{ml}$ of a non-defined (ND) medium consisting of $0.3 \%(\mathrm{w} / \mathrm{v})$ tryptone (Difco), $2.0 \%(\mathrm{w} / \mathrm{v})$ malt extract (Difco) and $4.0 \%(\mathrm{w} / \mathrm{v})$ reagent grade glucose. After autoclaving, the $\mathrm{pH}$ of the medium was $5^{\circ} \mathrm{O}$. The inoculum was an aqueous suspension of conidia filtered through glass wool before dispensing ( $0.1 \mathrm{ml} /$ flask). General Electric cool white fluorescent bulbs suspended above the flasks provided 4.04 to $4.3 \mathrm{I} \mathrm{klx} \mathrm{(375} \mathrm{to} 400 \mathrm{ft}$-candle), as ascertained by a Weston light meter. Dark cultures were kept in a light-tight box. Temperature in both instances was $25 \pm 2{ }^{\circ} \mathrm{C}$. Growth was measured by harvesting the pads at intervals, washing in a Buchner funnel fitted with a circle of paper towel, peeling off the pads and drying them to constant weight at $80{ }^{\circ} \mathrm{C}$.

Measurement of glucose and ${ }^{14} \mathrm{C}$. Glucose was measured by the glucose oxidase method (Worthington Biochemical Company, Freehold, New Jersey, U.S.A.). Respired ${ }^{14} \mathrm{CO}_{2}$ was measured by the method of Harrison, Wright \& Morita (197I), and mycelial ${ }^{14} \mathrm{C}$ by the 
method of O'Brian (1964). Adenosine triphosphate (ATP) was from Sigma; all radioactive chemicals were from Nuclear Chicago, Chicago, Illinois, U.S.A.

Preparation of crude extracts and measurement of glucose phosphorylation. Crude extracts were prepared from mould pads grown in $125 \mathrm{ml}$ Erlenmeyer flasks containing $10 \mathrm{ml} \mathrm{ND}$ liquid medium. Pads were harvested at intervals in a Buchner funnel, washed with distilled water, pressed dry between paper towels and weighed. Mycelium ( $\mathrm{g}$ fresh wt) was ground in a mortar over ice, with aluminium oxide as the abrasive, to form a thick paste; a slurry was made by adding $0.05 \mathrm{M}$-phosphate buffer, $\mathrm{pH} 7.0$ (3 to $5 \mathrm{ml})$; the crude extract was centrifuged at $\mathrm{I} 500 \mathrm{~g}$ for $\mathrm{I} 0 \mathrm{~min}$ at $4{ }^{\circ} \mathrm{C}$; and the supernatant was decanted and brought to $8.0 \mathrm{ml}$ with phosphate buffer. A portion ( $\mathrm{I} \mathrm{ml}$ ) of this extract was assayed immediately, and the remainder dialysed overnight against $200 \mathrm{ml}$ phosphate buffer at $4{ }^{\circ} \mathrm{C}$. Phosphorylated $\left[{ }^{14} \mathrm{C}\right]$ glucose was assayed by the method of Romano et al. (I970) modified in the following manner: samples $(\mathrm{I} \cdot \mathrm{C} \mathrm{ml})$ of the dialysed or undialysed extracts were added to a reaction mixture consisting of $0.03 \mathrm{M}-\mathrm{KF}, 0.0 \mathrm{I} \mathrm{M}-\mathrm{MgCl}_{2}$, $0.0 \mathrm{I} \mathrm{M}-\mathrm{ATP}$, and $0 . \mathrm{I} \mu \mathrm{Ci}$ of $\left[\mathrm{U}-{ }^{14} \mathrm{C}\right] \mathrm{glucose}$ $\left(4.8 \mathrm{mCi} \mathrm{mmol}^{-1}\right)$, with the $\mathrm{pH}$ adjusted to $7 \cdot 0$. After incubation for $30 \mathrm{~min}$ at $30^{\circ} \mathrm{C}$ in either light or darkness, the incubation mixture was frozen, thawed then centrifuged at I I $000 \mathrm{~g}$ for Io min at $4{ }^{\circ} \mathrm{C}$. Samples $(0.5 \mathrm{ml})$ of the resulting supernatants were added to a Bio-Rad AG-I-2 column $(0.5 \times 5.0 \mathrm{~cm})$ in the formate form, and the column was washed with $5^{\circ} 0 \mathrm{ml}$ distilled water followed by $5.0 \mathrm{ml}$ ammonium formate buffer $(0.5 \mathrm{M}-$ ammonium formate in $0.2 \mathrm{M}$-formic acid). A portion ( $\mathrm{I} \mathrm{ml}$ ) of each fraction was added to O'Brian's fluor ( $15 \mathrm{ml}$ ) and counted.

Estimation of conidia. Conidia were harvested by decanting the growth medium from the flasks, inserting a filter paper wick under the mycelial pad to remove as much medium as possible, and then adding $\mathrm{CCl}_{4}\left(5^{\circ} \mathrm{O} \mathrm{ml}\right)$ to suspend the conidia. Pads were washed twice with $\mathrm{CCl}_{4}(5.0 \mathrm{ml})$, the washings were pooled, and the extinction at $4 \mathrm{I} 0 \mathrm{~nm}$ of the resulting suspension was measured in a Spectronic 20 spectrophotometer.

\section{RESULTS}

When the organism was grown on ND medium solidified with $\mathrm{I} \cdot 5 \%(\mathrm{w} / \mathrm{v})$ agar under continuous light in a Petri dish, conidia were formed; but none were produced on darkgrown mycelium and faster radial growth occurred in continuous darkness (Fig. I). Exposure to light of a 2-day-old dark-grown culture for at least $3 \mathrm{~h}$ resulted in the development of a small ring of conidia during the following $12 \mathrm{~h}$ of dark incubation. Alternating light and dark periods produced bands of conidia.

Growth in ND liquid medium is illustrated in Fig. 2. Maximum dry weight was reached in 4 days in continuous light while growth in continuous darkness went on increasing for 6 days.

It is possible that light limited growth by inhibiting the uptake of an essential metabolite. Thus the capacity of the organism to utilize glucese was tested since this was the only defined component in the medium. The results (Fig. 3) indicated that the organism utilized about $23 \%$ of the available glucose when incubated in constant light, but almost completely utilized it when grown in the dark.

The onset of conidiation was apparent during the third day of exposure to light (Fig. 4). When conidiation was about half completed, glucose uptake ceased. Addition of labelled glucose to the medium at specified times during the development of conidia revealed a sharp decline in the rate of glucose uptake preceding the formation of the first measurable conidia (Fig. 5). On the fourth day, when conidiation was over half completed, there was little 


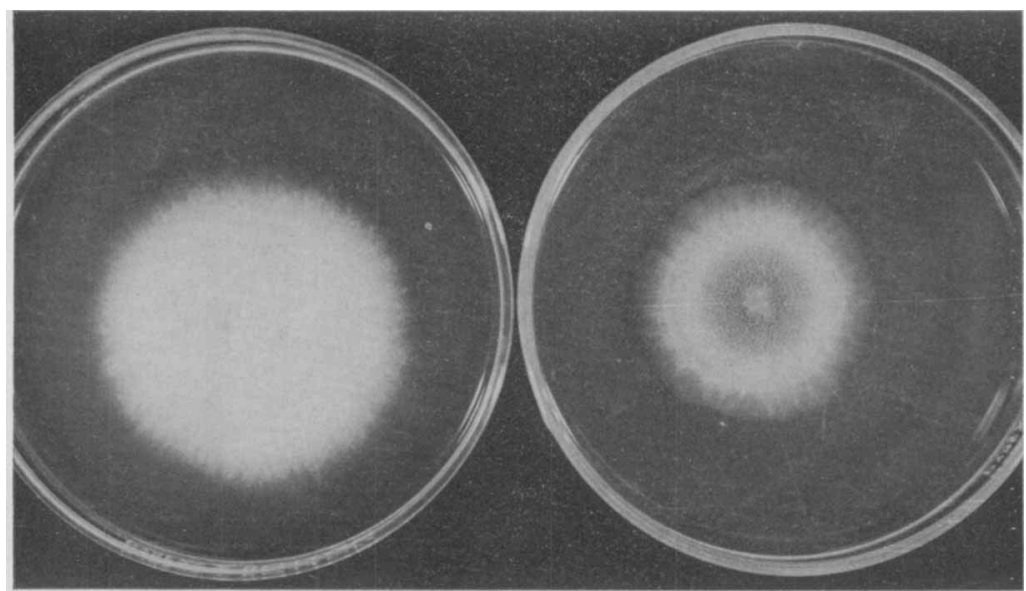

Fig. I. Aspergillus ornatus grown for 5 days on ND medium solidified with $\mathrm{I} \cdot 5 \%(\mathrm{w} / \mathrm{v})$ agar. The culture on the left was kept in continuous darkness and that on the right was exposed to continuous light. The colony on the left lacks conidia while the colony on the right has prcduced conidia at the centre. The colony on the left shows more radial growth than the one on the right.

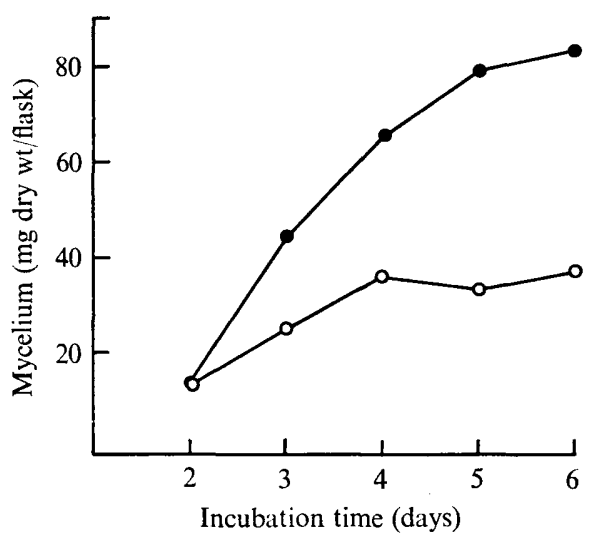

Fig. 2

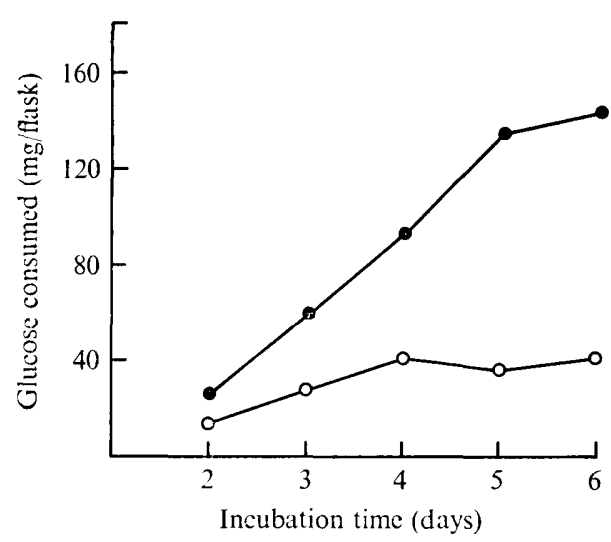

Fig. 3

Fig. 2. Growth curves of Aspergillus ornatus, grown in $25 \mathrm{ml}$ Erlenmeyer flasks containing $4.0 \mathrm{ml}$ of ND liquid medium in continuous darkness $(O)$ or in continuous light $(O)$. All points are averages of duplicate flasks.

Fig. 3. Total uptake of glucose from ND liquid medium by Aspergillus ornatus during growth in continuous darkness $(O)$ and continuous light $(O)$. Initial content of glucose in each flask was $170.0 \mathrm{mg}$.

glucose uptake, and when conidiation was completed on the fifth day virtually all of the labelled glucose had been respired.

After 4 days incubation in constant light, growth ceased, glucose uptake was greatly diminished and conidia production was more than half completed. This indicated that light had an inhibitory effect on uptake mechanisms as measured by glucose uptake, and that the organism is metabolically inactive except for the formation of conidia. To determine whether the organism could utilize other substrates, several ${ }^{14} \mathrm{C}$-labelled amino acids were fed separately in an identical manner to glucose. Most of these were utilized in the same way as glucose. However, the rate of uptake of $\left[\mathrm{U}^{14} \mathrm{C}\right]$ lysine increased with growth in continuous 


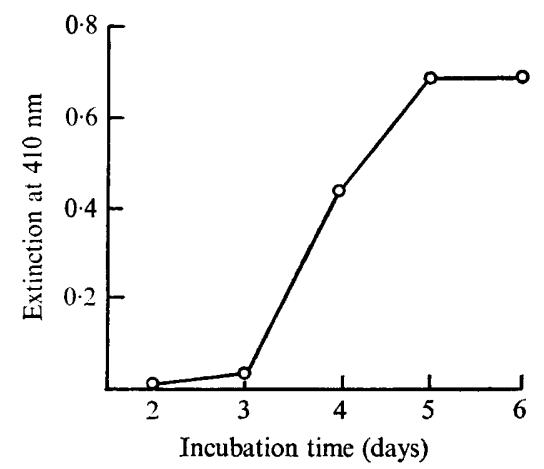

Fig. 4

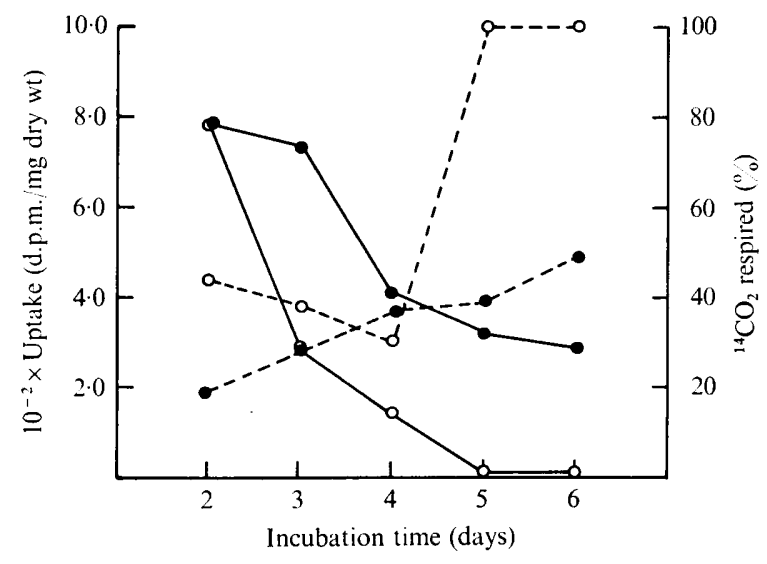

Fig. 5

Fig. 4. Production of conidia by Aspergillus ornatus during growth in ND liquid medium exposed to continuous light. No data are shown for continuous dark exposure since measurable amounts of conidia were not produced.

Fig. 5. Rate of uptake of $\left[\mathrm{U}^{-14} \mathrm{C}\right]$ glucose by Aspergillus ornatus. Labelled glucose $(0 \cdot 2 \mu \mathrm{Ci}, 0 \cdot 2 \mathrm{ml}$, $4.8 \mathrm{mCi} \mathrm{mmol}^{-1}$ ) was added to duplicate flasks and a control flask at specified times and incubated in either the light or dark at $25^{\circ} \mathrm{C}$ for $2 \mathrm{~h}$. The duplicates were averaged and corrected from the control. - U U - Utake by the organism during incubation in continuous darkness; $0-0$, uptake by the organism during incubation in continuous light. - - - - Percentage of assimilated $\left[{ }^{14} \mathrm{C}\right]$ glucose respired as ${ }^{14} \mathrm{CO}_{2}$ by the organism during incubation in continuous darkness; ${ }_{---}$, percentage of assimilated $\left[{ }^{14} \mathrm{C}\right]$ glucose respired as ${ }^{14} \mathrm{CO}_{2}$ by the organism during incubation in continuous light.

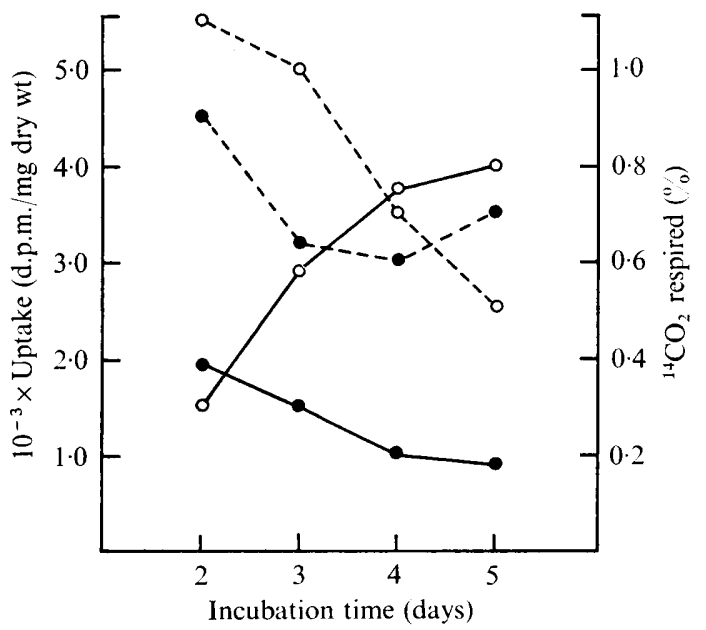

Fig. 6. Rate of uptake of $\left[\mathrm{U}^{-14} \mathrm{C}\right]$ lysine $\left(270 \mathrm{mCi} \mathrm{mmol}^{-1}\right)$ by Aspergillus ornatus. Conditions, procedures and symbols were as in Fig. 5 except the incubation time was $\mathrm{I} h$.

light, but decreased with growth in the dark (Fig. 6). In both instances, less than $2 \cdot 0 \%$ of the total amount of lysine taken up was respired.

Although light did not inhibit all uptake mechanisms, it is apparent that it diminished the rate of glucose uptake before growth ceased and conidia were produced. Since one of the first steps in glucose metabolism is its phosphorylation, the capacity of the organism to 
Table I. Phosphorylation of $\left[U-{ }^{14} C\right]$ glucose by crude extracts prepared from Aspergillus ornatus

Glucose phosphorylation was assayed, as described in Methods, in cultures grown continuously in the light or dark, or in cultures grown for $48 \mathrm{~h}$ in the dark, followed by transfer to light.

$\begin{array}{lcc}\text { Treatment } & \begin{array}{c}\text { Undialysed } \\ \text { extract }\end{array} & \begin{array}{c}\text { Dialysed } \\ \text { extract }\end{array} \\ 48 \text { h light } & 72 & 95 \\ 48 \text { h dark } & 64 & 94 \\ 48 \text { h dark +2 h light } & 78 & 94 \\ 48 \text { h dark+4 h light } & 59 & 94 \\ 48 \text { h dark+8 h light } & 45 & 90 \\ 48 \text { h dark+24 h light } & 47 & 90 \\ 48 \text { h dark +30 h light } & 56 & 92 \\ 78 \text { h light } & 43 & 93 \\ 78 \text { h dark } & 83 & .94\end{array}$

perform this function was tested. To determine if light would 'switch off' glucose phosphorylation, the organism was grown in the dark for 2 days and then transferred to the light. Crude extracts were prepared at intervals and their capacity to phosphorylate glucose was determined. There was a gradual decrease in glucose phosphorylation, which reached a minimum after $8 \mathrm{~h}$ of exposure to light (Table $\mathrm{r}$ ). This suggests that an inhibitor of glucose phosphorylation was produced or accumulated in the light. However, attempts to induce conidiation in the dark with extracts from light grown mycelium have not been successful.

\section{DISCUSSION}

The results indicate that light induces the formation of a dialysable inhibitor that blocks the phosphorylation of glucose. This reduces growth and leads to the formation of conidia. However, these events are not necessarily related since inhibitors such as cycloheximide and 5 -fluorouracil can inhibit growth by as much as $50 \%$ in the dark without the formation of conidia (unpublished observations). On the other hand, Schwemmin (1960) showed that when glucose was limiting, in the dark, growth was restricted and conidia were formed. These observations suggest that there is an internal threshold of glucose concentration that is necessary to prevent conidiation regardless of whether or not the organism was grown in the light.

Inhibitors that act as a functional part of control mechanisms for morphogenesis have been reported for Dictyostelium discoideum (Bacon, Sussman \& Paul, I973), Trichoderma viride (Galun \& Gressel, I966), Blastocladiella emersonii (Schmoyer \& Lovett, 1969) and Allomyces arbuscula (Burke, Seale \& McCarthy, 1972). Most of these are substances involved in RNA metabolism. On the other hand, some methylated xanthines can alter morphogenesis in Neurospora (Feldman, I975). Furthermore, light is known to affect some enzymes involved in cyclic-AMP metabolism which stimulates fruiting body formation in Coprinus macrorhizus (Uno \& Ishikawa, I974); Uno, Yamaguchi \& Ishikawa, 1974), and to affect the response of the sporangiophore of Phycomyces blakesleeanus (Cohen, 1974).

The production of bands of conidia, resulting from alternating light and dark periods, suggests that the inhibitor is localized in the hyphal tips and not translocated. That the banding effect may be the result of an inhibitor of glucose uptake is supported by the finding 
of Halaban (1975) who has shown that banding in a mutant of Neurospora is due to glucose transport deficiency. Although the nature of the inhibitor in A. ornatus is unknown, it appears to be specific for glucose metabolism since it does not affect some other metabolites such as lysine. The characterization of the inhibitor and the mechanism of its action is being investigated.

This work was supported by Research Corporation (Brown-Hazen fund) and National Science Foundation grant GY 3888. I wish to thank Professor Richard Y. Morita, Oregon State University, who provided laboratory facilities and assistance for part of this work.

\section{REFERENCES}

Bacon, C. W., Sussman, A. S. \& Paul, A. G. (1973). Identification of a self-inhibitor from spores of Dictyostelium discoideum. Journal of Bacteriology 113, 106I-I063.

Burke, D. J., Seale, T. W. \& McCarthy, B. J. (1972). Protein and ribonucleic acid synthesis during the diploid life cycle of Allomyces arbuscula. Journal of Bacteriology 110, 1065-1072.

Carlile, M. J. (1965). The photobiology of fungi. Annual Review of Plant Physiology 16, 175-202.

Carlile, M. J. (I970). The photoresponses of fungi. In Photobiology of Micro-organisms. pp. 309-344. Edited by P. Halldal. London: Wiley.

Cohen, R. J. (1974). Cyclic AMP levels in Phycomyces during response to light. Nature, London 251, 144-I46

Feldman, J.F. (1975). Circadian periodicity in Neurospora: alteration by inhibitors of cyclic AMP phosphodiesterase. Science, New York 190, 789-790.

Galun, E. \& Gressel, J. (1966). Morphogenesis in Trichoderma: suppression of photoinduction by 5-fluorouracil. Science, New York I5I, 696-698.

Gressel, J. \& Galun, E. (1967). Morphogenesis in Trichoderma: photoinduction and RNA. Developmental Biology 15, 575-598.

Halaban, R. (I975). Glucose transport-deficient mutant of Neurospora crassa with an unusual rhythmic growth pattern. Journal of Bacteriology 121, 1056-1063.

Harrison, J., Wright, R. T. \& Morita, R. Y. (I971). Method for measuring mineralization in lake sediments. Applied Microbiology 21, 698-702.

Muntanjola-Cvetkovic, M. \& Neskovic, M. (I968). Studies on the effect of some substances as possible substitutes of light in the sporulation of Aspergillus flavus 28-A. Bulletin de L'Institut et du Jardin Botanique de L'Université de Belgrade 3, I-4, 35-4I.

O'Brian, R. D. (1964). Nitric acid digestion of tissues for liquid scintillation counting. Analytical Biochemistry 7, 25I-254.

Raper, R. B., Fennell, D. E. \& Treasner, H. D. (1953). The ascosporic stages of Aspergillus citrosporus and related forms. Mycologia 45, 67I-692.

Romano, A. H., Eberhard, S. J., Dingle, S. L. \& McDowell, T. D. (I970). Distribution of the phosphoenolpyruvate:glucose phosphotransferase system in bacteria. Journal of Bacteriology 104, 808-8 I3.

SChmoyer, I. R. \& LovetT, J. S. (I969). Regulation of protein synthesis in zoospores of Blastocladiella. Journal of Bacteriology 100, 854-864.

Schwemmin, D. J. (1960). Light controlled reproductive differentiation in Aspergillus ornatus. Ph.D. thesis, University of Michigan, U.S.A.

Uno, I. \& Ishikawa, T. (1974). Effect of glucose on the fruiting body formation and adenosine $3^{\prime}: 5^{\prime}$-cyclic monophosphate levels in Coprinus macrorhizus. Journal of Bacteriology 120, 96-1oo.

Uno, I., Yamaguchi, M. \& Ishikawa, T. (1974). The effect of light on fruiting body formation and adenosine $3^{\prime}: 5^{\prime}$ cyclic monophosphate metabolism in Coprinus macrorhizus. Proceedings of the National Academy of Sciences of the United States of America 7r, 479-483. 